\title{
The intercultural competence of preservice teachers: An exploratory study
}

\section{Beutel, Denise and Tangen, Donna}

Faculty of Education, Queensland University of Technology, Australia

\begin{abstract}
This paper presents the findings of a qualitative study that explored the impact that prior intercultural experiences have in shaping preservice teachers as teachers of diversity. An online qualitative questionnaire was used to collect data from preservice teachers $(n=40)$ enrolled in a one year graduate entry teacher education program in eastern Australia. Hammer's (2009, 2011) Intercultural Development Continuum (IDC) was used as a framework to analyse the data. The IDC is a model of intercultural competence used to explain how people interpret cultural difference (Hammer, Bennett \& Wiseman, 2003). Each of the five positions on the continuum has a distinct set of perceptions and experiences around cultural differences. In presenting the results, we draw on several cases that encompass the breadth of prior intercultural experiences of the preservice teachers. Overall, the results indicate that sustained intercultural engagement over time provides opportunity for the development of greater intercultural sensitivity. While it is advocated that teacher education is wellpositioned to play a key role in developing the intercultural comptetences of future teachers, the paper highlights the challenges in providing learning opportunities that allow preservice teachers to practice new ideas, challenge old ideas and reflect on the process of becoming inclusive educators.
\end{abstract}

Keywords: intercultural competence; diversity; preservice teacher; teacher education 


\section{Introduction}

The diversity of students in school classrooms across the globe has increased significantly over the past decade. This broadening of diversity may be attributed in part to globalisation and the increased mobility of populations across the world. Added to this, inclusive education has become a key education agenda internationally. The inclusive education movement emerged from declarations such as 1948 Universal Declaration of Human Rights (United Nations,1948), the World Declaration on Education for All (UNESCO, 1990) and the Salamanca Statement and Framework for Action (UNESCO, 1994). The principal premise of these core policies is that education is the right of all children. In its broadest interpretation, inclusive education encompasses children regardless of race, ethnicity, disability, gender, sexual orientation, language, socio-economic status, and any other aspect that might be perceived as different (Polat, 2011). However, while student populations have become increasingly diverse in areas of ethnicity, culture, languages and disability, the profile of the teaching workforce has remained relatively static (Florian, 2012). In Australia, the teaching workforce has remained largely Anglo-ethnic (Han \& Singh, 2007) while student populations have widened in response to increasing numbers of migrants from different cultural and ethnic groups and the implementation of inclusive education policies and practices. It is an expectation that teachers cater for all students in their classrooms. However, concerns have been expressed that beginning teachers are illprepared to meet the needs of the diversity of students in their classrooms.

Kumar and Hamer (2013) attribute the lack of preparedness to poor preparation in teacher education programs. Having hands-on experiences such as participation in outbound mobility programs do not guarantee positive intercultural development (Dockrill, Rahatzad, \& Phillion, 2015). Indeed, negative stereotypes can be confirmed if preservice teachers feel challenged or threatened in working with different cultures (Tang \& Choi, 2004). We argue that because the majority of preservice teachers in Australia lack opportunity to undertake international experiences in their courses, teacher educators need to understand how their backgrounds, prior intercultural learning and experiences can be utilised to better prepare them for teaching diverse learners. This qualitative study $(\mathrm{n}=40)$ draws on Hammer's (2009) Intercultural Development Continuum to explore the impact that prior intercultural experiences have on shaping preservice teachers as teachers of diversity. We present several case studies that encompass a range of prior intercultural experiences to posit how teacher education can better prepare preservice teachers for engaging diverse learners.

\section{Theoretical framework}

A review of the literature has revealed an extant body of research exploring preservice teachers' preparedness for teaching students with disabilities. However, Florian (2012) 
identifies that teacher education must also consider the increasing cultural and linguistic diversity presented by students in classrooms. This change in narrative about inclusion means that educators need to think beyond learning difficulties and disabilities and include the notion of intercultural difference. Developing intercultural competence has been widely studied. In a major review researchers for UNESCO (2013) described intercultural competence as having the resources to negotiate cultural boundaries through personal experiences and encounters. Developing intercultural competence 'fees' individuals from their own logic and cultural idioms to engage and interact with cultural 'others'. In doing so, individuals have the opportunity to explore their own identities.

The Intercultural Development Continuum (IDC) (Hammer, 2011) is a model of intercultural competence used to explain how people interpret cultural difference (Hammer, Bennett \& Wiseman, 2003). Hammer's IDC considers intercultural competence as falling on a developmental continuum progressing from monocultural (or ethnocentric) mindsets of denial and polarisation through a transitional orientation of minimization towards the more intercultural (or global) mindsets of acceptance and adaptation (Hammer, 2011). Each of the five positions on the continuum has a distinct set of perceptions and experiences around cultural differences (Hammer, 2009). Once advanced to a more global mindset, regression to a more monocultural mindset is unlikely.

Several key factors facilitate the progression along the IDC to more global mindsets. Immersion in a different cultural context from one's own is insufficient to develop a more intercultural mindset (Paige \& Vande Berg, 2012). To progress interculturally, individuals must be open to the ideas, beliefs and values of others, critically reflect on their own position about interculturality and actively seek out intercultural experiences, in one's personal life and through educational experiences, and seek out support groups who can both challenge and nourish intercultural sensitivities (Garmon, 2004). Further, these opportunities must be differentiated to align with the level of readiness of individuals.

\section{Methods}

\subsection{Participants}

Forty preservice teachers enrolled in a one-year graduate-entry teacher education program in a large Australian university participated in this study. All participants were enrolled in the core subject, Engaging Diverse Learners, generally taken in the first semester of the program. The focus in the subject is on developing preservice teachers' knowledge and understanding of the theories and principles relating to the provision of socially just education, creating supportive learning environments for the diversity of learners in classrooms and the application of these principles to classroom practices. 


\subsection{Data collection and analysis}

Data were collected for this qualitative study using an online questionnaire. A link to the questionnaire was sent out via the subject Blackboard site in the first two weeks of the semester. One reason for the timing of the survey was to better understand the range of intercultural competence the students had; this information allowed the subject coordinator to refine the focus of subsequent lessons about engaging diverse learners. The researchers drew on Hammer's (2009) IDC orientations to develop items for the questionnaire. The first part of the questionnaire comprised questions that collected demographic data including the age range, parental status and gender of the respondents. The remaining questions were open-ended and provided the opportunity for preservice teachers to give extended responses. Questions posed inquired about who provided their inspiration for becoming a teacher and the image they had of themselves as the teacher they aspired to become. Further questions focused on the qualities or strengths that they perceived they had to engage effectively with the diversity. These questions also required the preservice teachers to recall and reflect upon their prior experiences with diversity providing examples of their intercultural engagement.

The data were analysed following release of grades for the subject as per the university ethics requirements. Creswell's (2014) six-stage process of content analysis was used to analyse the data. First, each researcher read and re-read the complete set of data independently. In this process, the complete set of responses for each questionnaire was examined as well as analysing the whole set of responses for each individual question. Following the initial independent analysis, the researchers collaboratively discussed the data in relation to the intercultural orientations of Hammer's (2009) model of IDC.

\section{Findings and discussion}

Using the lens of Hammer's IDC (2009) this research explored the impact that prior intercultural experiences have in shaping preservice teachers as future teachers of diversity. Table 1 shows the intercultural orientations of the participants in the study. In discussing the findings, we use the responses of three participants, Hannah, Ben and Aaron (pseudonyms), to illustrate the nuances between positions on Hammer's IDC. The first case is Hannah, a female preservice teacher aged between 31 and 40. Hannah was born outside of Australia and was raised in a "country where there are now eleven official languages". Attending primary and high schools that were highly multilingual and multicultural, she commented that "Adapting to other cultures and languages became a necessary way of life, and anyone who did not adapt and tried to live in isolation tended to get left behind" For Hannah, moving to Australia, was "quite a culture shock, not from the differences, but from the monotony. I find it odd that one has to formally be taught how to adapt to a 
multicultural group, how to think from another person's cultural perspective”. Here Hannah is referring to the need for Australian students to undertake a unit called, Engaging Diverse Learners, as diversity was always a part of her personal history. Since settling in Australia, Hannah indicated that she has actively sought out engagement with diverse cultural groups. However, Hannah acknowledged that she knew little of Australian Indigenous culture but followed up with "It is a learning gap that I will have to fill...quickly". Embedding Australian Indigenous perspectives is a key component of the Australian curricululm. She describes an acceptance of living and working with different cultural groups both in her home country and in Australia. Further, as a preservice teacher, she appeared highly motivated to understand the "culture of learning from which my students come, where they are in life, what their expectations are", indicating a culturally aware approach to teaching consistent with an intercultural mindset. Hannah expressed interest in, and acceptance of, other cultures while also having an awareness that she will need to adapt her pedagogy according to the cultural contexts of her students. Thus, it appears that Hannah's positioning on the IDC would be at the intercultural (or global) end between the acceptance and adaptation orientations. A shift from acceptance to adaptation, involves deepening one's own perceptions of other cultures, demonstrating an understanding of different cultural practices (even those that are confronting and opposed to one's own personal values) and an increased capability to make ethical judgements taking into consideration the disparity between different cultural values (Hammer, 2009). An adaptation orientation, involves the capability to shift perspective to another culture and to adapt behaviour according to the cultural context (Hammer, 2009).

We contrast Hannah's case with that of two male preservice teachers, Ben and Aaron. Aaron has no children and is aged between 41 and 50. Unlike Hannah, Aaron was born in Australia. However, similar to Hannah, he describes a variety of intercultural experiences such as "attending school in several different countries including the United Kingdom, Saudi Arabia, Botswana, Papua New Guinea as well as travelling extensively during his school years". Beyond his schooling years, Aaron "went to PNG to work for 6 months in community development then, back in Australia, worked in a company working with Aboriginal communities". Following this, he went to South Korea to teach ESL for 10 years, then worked with Ausaid in Bangladesh and finally returning to Brisbane he has continued teach ESL noting that "Brisbane's ESL students are pretty diverse ethnically". It appears that Aaron has a wide and ongoing engagement with diversity. When asked what qualities he had to teach a diverse group of learners, he focused on the nuances of intercultural interactions "Little things matter - like saying people's names properly, I've had French, Colombian, Venezuelan, Sri Lankan, Indian, Thai and Iranian in one class before - it can be challenging - but if you let your students know you respect them it goes a long way". Further responses from Aaron confirmed respect and tolerance "I'll have to be vigilant that I remain open-minded and tolerant of all". Aaron also described the need for 
good communication skills to effectively interact with all his students. From this evidence, we can position Aaron within the intercultural orientation of acceptance. Of the 40 participants, 19 ( $\mathrm{n}=6$ males and $\mathrm{n}=13$ females) demonstrated an acceptance orientation. People with an acceptance orientation identify how cultural differences operate in situations that involve human interactions. As Bennett (2004) comments, acceptance allows a person to "take the perspective of another culture without losing your own perspective" (p. 70). While Aaron appears to have an intercultural mindset, Hannah was the only participant able to imagine how she would negotiate her cultural orientation with being in the classroom with her students, accepting them on their own terms and indeed learning from them.

Table 1: Intercultural orientations of the participants

\begin{tabular}{|c|c|c|c|c|c|}
\hline & Denial & Polarisation & Minimisation & Acceptance & Adaptation \\
\hline Male & Age $26-30 \times 1$ & & $\begin{array}{l}\text { Age } 21-25 \times 2 \\
\text { Age } 26-30 \times 1 \\
\text { Age } 31-40 \times 2 \\
\text { Age } 41-50 \times 1\end{array}$ & $\begin{array}{l}\text { Age } 21-25 \times 1 \\
\text { Age } 26-30 \times 3 \\
\text { Age } 41-50 \times 1 \\
\text { Age } 50+\times 1\end{array}$ & $\begin{array}{l}\text { Age } 26-30 \times 1 \\
\text { Age } 41-50 \times 1\end{array}$ \\
\hline Female & & & $\begin{array}{l}\text { Age } 26-30 \times 1 \\
\text { Age } 31-40 \times 3 \\
\text { Age } 41-50 \times 4 \\
\text { Age } 50+\times 1\end{array}$ & $\begin{array}{l}\text { Age } 21-25 \times 3 \\
\text { Age } 26-30 \times 3 \\
\text { Age } 31-40 \times 2 \\
\text { Age } 41-50 \times 4 \\
\text { Age } 50+\times 1\end{array}$ & Age $31-40 \times 3$ \\
\hline Total & 1 & 0 & 15 & 19 & 5 \\
\hline
\end{tabular}

Ben's story however is diametrically opposed to that of Aaron and Hannah and the other participants in the study. Ben, described himself as an Anglo-Australian aged between 26 and 30 who is also a parent. Ben described minimal interest and engagement with diversity. When asked to describe his prior experiences with diversity, he responded that "I did an environmental assessment for the Aurukun people that also included recording cultural practices and stories. I have one close friend with Autism (though he has it in a good way)". He did not describe what having autism 'in a good way' meant nor did he reflect on any intercultural impact working for the Aurukun people had on him. Ben, Hannah and Aaron live in a multicultural country (Australia). However, Ben was the only participant who chose not to engage with diversity, preferring instead to stick to his own cultural group thereby limiting his intercultural awareness and sensitivity. He commented that "throughout school/uni I would often make friends with people with different backgrounds. These friendships tended to trail off quickly and now all of my lasting friendships come from similar backgrounds to me". However, he did identify a need to "Improve my knowledge and understanding of other cultures while reflecting on my own culture, beliefs and prejudice". While a noble objective, it is not clear if Ben would have made such a 
determination for his teaching future if he was not enrolled in a subject named: Engaging Diverse Learners. Of all the participants, Ben was the only participant who exhibited an orientation of denial. His limited experiences with, and apparent distancing from, other cultures confirmed his monocultural orientation and denial mindset. His apparent lack of interest in pursuing engagement in intercultural experiences (Garmon, 2004) indicates that Ben's intercultural readiness (Marx \& Moss, 2011) might be quite low. While Hannah and Aaron expressed intercultural mindsets, Ben seemed reluctant to engage with diversity or to challenge his prior beliefs about engagement with cultural difference. Previous research (Garmon, 2004) has identified that some individuals resist opportunities to engage with diversity, expressing disinterest in other cultures. This monocultural orientation handicaps preservice teachers' effectiveness to engage diverse learners as fully included members of the classroom. The challenge for teacher education is to provide opportunities for individuals with monocultural orientations, like Ben, that prompt them to reflect deeply on cultural differences and challenge their current intercultural perspectives (Hammer, 2009).

\section{Conclusions}

The three preservice teachers identified in this paper described opportunities to participate in a range of intercultural activities before entering teacher education. However, previous research (Paige \& Vande Berg, 2017) indicates that immersion is insufficent alone to develop more sophisticated levels of intercultural competence. The findings, while only a snapshot of the range of diversity experienced by the group of preservice teachers, revealed that quality opportunities to interact with diversity over extended periods of time have the capacity to increase the development of intercultural sensitivity.

While we agree that teacher education programs must be intentional in their efforts (Bustamante et al., 2016) to develop preservice teachers' intercultural competence, we ponder how rigorous and extended opportunities for developing intercultural capacity can be built into a one-year program, particularly given the pre-existing monocultural mindsets of some individiuals entering the program. Further, we posit how to embed meaningful experiences into all teacher education programs to progress preservice teachers towards more intercultural mindsets. We suggest that providing learning opportunities and mentoring in both course work and through professional experience placements that allow preservice teachers to practice new ideas, challenge old ideas and reflect on the process of becoming inclusive educators for the whole range of diverse of learners is a starting point for developing greater intercultural competences with the next generation of teachers. 


\section{References}

Bennett, M. J. (2004). Becoming interculturally competent. In J. Wurzel (Ed.) Toward multiculturalism: A reader in multicultural education (2nd ed.), (pp. 62-77). Newton, MA: Intercultural Resource Corporation.

Bustamante, R. M., Skidmore, S. T., Nelson, J. A., \& Jones, B. E. (2016). Evaluation of a Cultural Competence Assessment for Preservice Teachers. The Teacher Educator, 51(4), 297-313.

Creswell, J. W. (2012). Educational Research: Planning, Conducting, and Evaluating Quantitative and Qualitative Research (4th ed.). Boston, MT: Pearson Education Limited.

Dockrill, H., Rahatzad, J., \& Phillion, J. (2015). The benefits and challengs of study abroad in teacher education in a neoliberal context. In J. A. Rhodes \& T. M. Milby (Eds.), Advancing teacher education and curriculum development through study abroad (pp. 290-305). Hershey, PA: IGI Global.

Florian, L. (2012). Preparing teachers to work in inclusive classrooms: Key lessons for the professional development of teacher educators from Scotland's inclusive practice project. Journal of Teacher Education, 63(4), 275-285.

Garmon, M. A. (2004). Changing preservice teachers' attitudes/beliefs about diversity. What are the critical factors? Journal of Teacher Education, 55(3), 201-213.

Hammer, M. R. (2009). The Intercultural Development Inventory In: M. A. Moodian (Ed.), Contemporary Leadership and Intercultural Competence (pp. 203-217). Thousand Oaks, CA: Sage.

Hammer, M. R. (2011). Additional cross-cultural validity testing of the Intercultural Development Inventory. International Journal of Intercultural Relations, 35(4), 474487.

Hammer, M. R., Bennett, M. J., \& Wiseman, R. (2003). Measuring intercultural sensitivity: The intercultural development inventory. International Journal of Intercultural Relations, 27(4), 421-443.

Han, J., \& Singh, M. (2007). Getting World English Speaking student teachers to the Top of the Class: Making hope for ethno-cultural diversity in teacher education robust. AsiaPacific Journal of Teacher Education, 35(3), 291-309.

Kumar, R. \& Hamer, L. (2013). Preservice teachers' attitudes and beliefs toward student diversity and proposed instructional practices: A sequential design study. Journal of Teacher Education, 64(2), 162-177.

Marx, H., \& Moss, D. M. (2011). Please mind the culture gap: Intercultural development during a teacher education study abroad program. Journal of Teacher Education, 62(1), 35-47.

Paige, R. M., \& Vande Berg, M. (2012). Student learning abroad: What our students are learning, what they're not, and what we can do about it. Hendon, VA: Stylus Publishing.

Polat, F. (2011). Inclusion in education: A step towards social justice. International Journal of Educational Development, 31(1), 50-58. 
Tang, Y. F. S., \& Choi, P. L. (2004). The development of personal, intercultural and profressional competence in international field experience in initial teacher education. Asia Pacific Education Review, 5(1), 50-63.

United Nations Educational, Scientific and Cultural Organisation (UNESCO). (2013). Intercultural Competence. Conceptual and Operational Framework. BSP-2012/WS/9

UNESCO. 1990. World Declaration on Education for All. Paris:Author.

UNESCO (1994). The Salamanca Statement and Framework for Action on Special Needs Education. Adopted by the World Conference on Special Needs Education, 7-10 June, in Salamanca, Spain.

United Nations (1948). Universal declaration of human rights. Retrieved on February 11 2012 from http://www.un.org/Overview/rights.html 